\title{
PP-coir Composites (PPCC): Fabrication and Study of Flexural Properties
}

\author{
Md. Nazrul Islam ${ }^{1, ~ *, ~ M . ~ A . ~ G a f u r ~}{ }^{2}$ \\ ${ }^{1}$ Department of Physics, Primeasia University, Banani, Dhaka, Bangladesh \\ ${ }^{2}$ Pilot Plant and Process Development Center, BCSIR, Dhaka, Bangladesh
}

Email address:

n_islam58@yahoo.com (Md. N. Islam)

${ }^{*}$ Corresponding author

To cite this article:

Md. Nazrul Islam, M. A. Gafur. PP-coir Composites (PPCC): Fabrication and Study of Flexural Properties. Modern Chemistry. Vol. 7, No. 4, 2019, pp. 114-117. doi: 10.11648/j.mc.20190704.15

Received: August 8, 2019; Accepted: October 31, 2019; Published: December 4, 2019

\begin{abstract}
Today we are more concern about the environment. Synthetic polymers are the most responsible pollutant for environmental pollution. Good replacing agents for the synthetic polymers are the natural polymer. That is why the uses of natural fiber reinforced composites are increasing day-by-day. In this research natural polymer coir fiber was used as the reinforcing agent with the synthetic polymer polypropylene. PP-coir composites were fabricated using a simple hot press molding method. The prepared composites were characterized by the density, tensile, and flexural properties. The effect of fiber addition on some physical and mechanical properties was evaluated. The density increases with the increase of fiber addition. The tensile strength of fabricated product increases with the increase of fiber addition up to $10 \%$ (wt.) and then decreases continuously. The elongation of fabricated product decreases with the increase of fiber addition continuously. The changes in the mechanical properties were broadly related to the accompanying interfacial bonding of PP- coir composites (PPCC). It revealed that the introduction of short coir fiber led to a slightly improved thermo oxidative stability of PP- Coir composites. The flexural strain of fabricated product decreases continuously with the increase of fiber addition. But here untreated fiber reinforced composites show higher strain than that of treated fiber reinforced composites.
\end{abstract}

Keywords: Polypropylene, Coir, Composite, Mechanical Properties

\section{Introduction}

The use of natural fibers, derived from annually renewable source, as reinforcing fibers in both thermoplastic and thermosetting matrix composites provides positive benefits with respect to ultimate disposability and raw material utilization [1-6]. Coir fiber has received considerable attention for its diversified use both in academic and industrial research. Biodegradable plastics such as cellulose-based thermoplastics, aliphatic polyester etc. have attracted much attention in recent years from the point of view of environmental protection [2, 3] Natural fibers such as jute, coir, palm, banana etc. are used as an alternative to synthetic fibers e.g. glass, aramid, carbon, etc. These fibers are used due to their renewable character, acceptable specific strength properties, low cost, enhanced energy recovery, and biodegradability [7-13]. Natural fiber reinforced polymer combine good mechanical properties with low specific mass. The coir is widely used to as reinforcing agent in thermoplastics like polyethylene (PE), polypropylene (PP). The use of short coir fibers and their effects on properties are not well documented. Fiber reinforcement is an effective way to improve the mechanical properties of thermoplastics. Natural plant based lingo-cellulosic fibers are attractive reinforcing materials than the non degradable fibers like glass fiber, carbon fiber and aramid fiber etc $[14,15]$. A number of studies have been carried out on biodegradable thermoplastics reinforced with the fibers have been reported. The presence of hydroxyl and polar groups in various constituents of jute accounts for its high moisture region value [4], leads to poor adhesion with the polypropylene.

The objective of the study is to find out the fabrication process rout, optimize the process parameters and the effect of fiber addition on the flexural properties of coir-PP composites. In this research work we tried to find out the mechanical properties of coir fiber reinforced PP based composites. 


\section{Experimental Procedure}

\subsection{Raw Materials}

Coir fibers are collected from local market. Then they are cut (approx. size 2-3 $\mathrm{mm}$ in length) by cutter. PP is also collected from local market. Table 1 shows average chemical composition of coir fibers [2].

Table 1. Average chemical composition of coir fibers.

\begin{tabular}{ll}
\hline Cellulose & $\mathbf{4 3 . 4 4 \%}$ \\
\hline Hemicellose & $0.25 \%$ \\
Lignin & $45.84 \%$ \\
Pectin and relaed product & $3.00 \%$ \\
Water soluble & $5.25 \%$ \\
\hline
\end{tabular}

\subsection{Fabrication}

Mixing: A blender is used to mix the PP-coir for a period of 2 minutes at 500rpm.

Heating and Pressing: The PP-coir mixture is taken in $\mathrm{S} / \mathrm{S}$ mould. The heating and pressing are done by a $450 \mathrm{KN}$ Weber-Press. The press is consisted of pressing, heating and cooling system.

\subsection{Measurement of Properties}

Density: The bulk density of the composites is determined according to ASTM C135-76 by measuring the weight of the samples in the following way:

The tensile test was carried by a $10 \mathrm{KN}$ UTM. Figure 1 Shows the dimension of the tension test specimen. The speed of testing is $5 \mathrm{~mm} / \mathrm{min}$.
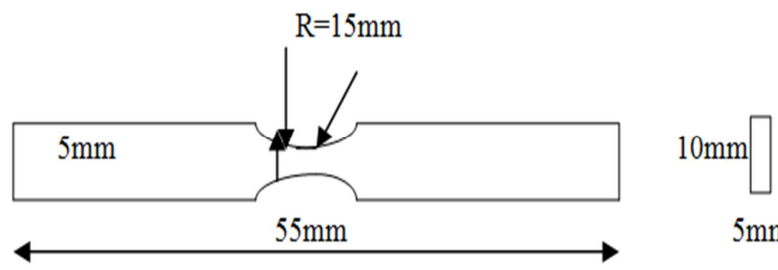

Figure 1. Tensile strength test specimen.

\section{Results and Discussion}

\subsection{Temperature, Pressure and Heating Time}

These are important parameters to obtain good product. A number of temperatures $\left(230^{\circ} \mathrm{C}, 245^{\circ} \mathrm{C}\right.$, and $\left.260^{\circ} \mathrm{C}\right)$ have been taken for fabrication. It has found that best samples have been obtained at $245^{\circ} \mathrm{C}$. The fiber found to be burnt out for higher temperature and polymerization has not been completed for lower temperature. The incompleteness has been recognized by granule structure of samples. Similarly, the load, heating time are optimized as $20 \mathrm{KN}$, and $30 \mathrm{~min}$.

\subsection{Flexural Strength}

The effect of fiber addition on flexural strength of PP-coir composites for treated and untreated fiber's shown in figure 2. It reveals that the flexural strength increases with the increase of fiber addition up to certain percentage of addition coir fiber (up to $5 \%$ ), afterwards the variation of flexural strength with composition is insignificant up to about $20 \%$ for treated fiber, the strength is always higher than that for untreated fiber. For $0 \%$ fiber the polymer strength was obtained 28 $\mathrm{MPa}$. Up to $10 \%$ fiber addition both the fiber and matrix bear the load and make resistance to slip as in the case of age hardening of metals. Up to $10 \%$ the short fibers are finely distributed and the interfacial bonding between the fiber and matrix is high, after that fibers are present as bundle of fibers and fiber-fiber bonding strength is lesser and the interfacial bonding between the fiber and matrix is poor. After that the fiber are coagulated as bundle of fibers, bundle of fibers fractured during load to slips and does not make resistance to slips. Moreover, these also act as stress concentrator. Consequently, after $10 \%$ fiber addition the flexural strength decreases.

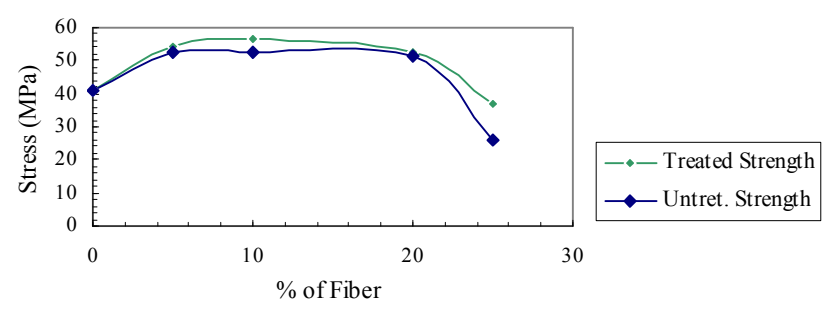

Figure 2. Effect of fiiber addition on flexular stress of PP-coir composites.

Table 2. Effect of fiber addition on normalized flexural strength.

\begin{tabular}{lll}
\hline $\begin{array}{l}\text { \%o of fiber } \\
\text { addition }\end{array}$ & $\begin{array}{l}\text { Normalized flexural } \\
\text { strength for treated fiber }\end{array}$ & $\begin{array}{l}\text { Normalized flexural } \\
\text { strength for untreated fiber }\end{array}$ \\
\hline 0 & 1.00 & 1.00 \\
5 & 1.3203 & 1.278 \\
10 & 1.375 & 1.285 \\
20 & 1.278 & 1.253 \\
25 & 0.9065 & 0.6288 \\
\hline
\end{tabular}

Table 2 shows that the maximum normalized strength is obtained at $10 \%$ fiber addition which 1.375 times for the treated coir fiber and 1.285 times for the untreated coir fiber of pure pp. It also shows that up to $20 \%$ the strength is higher than that of pure PP. Similar effect was found by Rashed and Rizvi [5], Shabname Ele [6], Bipasha Bose [3].

\subsection{Flexural Strain}

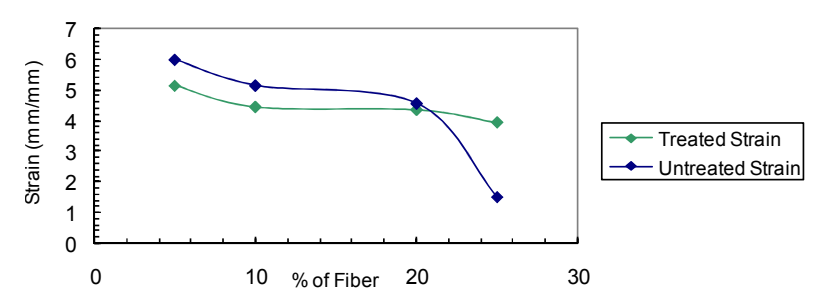

Figure 3. Effect of fiiber addition on flexular strain of PP-coir composites.

The effect of fiber addition on flexural strain of PP- coir composites for treated and untreated fiber have shown in figure 3. It reveals that the flexural strain of fabricated product decreases continuously with the increase of fiber addition. It is 
apparent that elongation decreases very slightly with the increasing fiber content.

Table 3. Effect fiber addition on Flexural strain.

\begin{tabular}{lll}
\hline \% of Fiber & $\begin{array}{l}\text { \% of Elongation for } \\
\text { treated fiber }\end{array}$ & $\begin{array}{l}\text { \%of Elongation for } \\
\text { untreated fiber }\end{array}$ \\
\hline 5 & 5.1437 & 5.99 \\
10 & 4.4453 & 5.1488 \\
20 & 4.3536 & 4.5598 \\
25 & 3.9342 & 1.4948 \\
\hline
\end{tabular}

The presence of fiber restricts the slip resulting in lesser ductility and consequently the $\%$ of elongation decreases continuously with the increase of fiber addition. Strain is lesser for treated than that for untreated per cross-sectional area. Similar effect was found by Shabname Ele [6].

\subsection{Tangent Modulus}

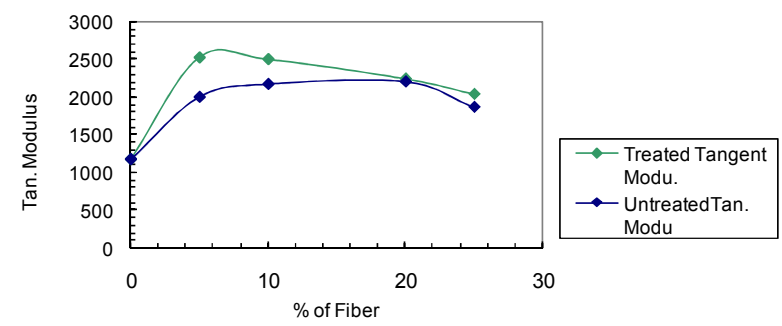

Figure 4. Effect of fiiber addition on tangential modulus of PP-coir composites.

Figure 4 shows the effect on Tangent modulus of PP-Coir composites for treated and untreated fiber. It reveals that the tangent modulus increases with the increase of fiber addition up to certain percentage of addition treated and untreated fiber and after it decreases. Up to this composition (increasing region) the fiber and the polymer are well distributed ${ }^{7}$.

Table 4. Effect of fiber addition on tangent modulus of PP-Coir composite.

\begin{tabular}{lll}
\hline \% of fiber & $\begin{array}{l}\text { Normalized Tangent } \\
\text { Modulus for treated fiber }\end{array}$ & $\begin{array}{l}\text { Normalized Tangent } \\
\text { Modulus for untreated fiber }\end{array}$ \\
\hline 0 & 1.00 & 1.00 \\
5 & 2.161 & 1.71 \\
10 & 2.1416 & 1.859 \\
20 & 1.92 & 1.887 \\
25 & 1.75 & 1.59 \\
\hline
\end{tabular}

Table 4 shows that the maximum normalized Tangent Modulus is obtained at $5 \%$ for treated fiber addition which 2.161 times of pure PP and $20 \%$ for untreated fiber which 1.887 times of pure PP. It also shows that up to $25 \%$ the tangent modulus is higher than that of pure PP.

\subsection{Young's Modulus}

Figure 5 shows the effect on Young's modulus of PP-Coir (treated and untreated fiber) composites. It reveals that the young's modulus increases with the increase of fiber addition up to certain percentage of addition treated coir (up to 20\%) and after it decreases. Up to this composition (increasing reason) the fiber and the polymer are well distributed.

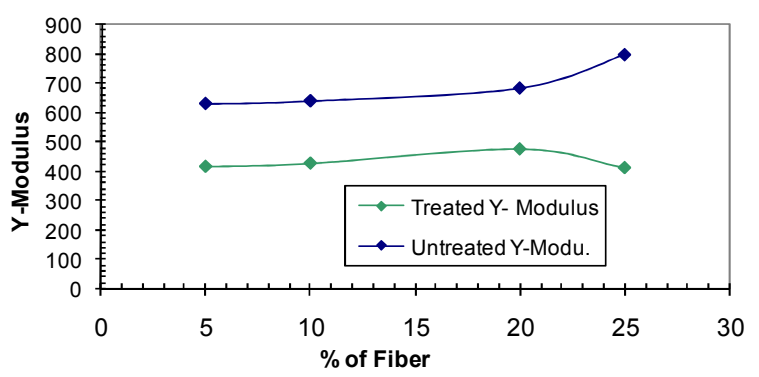

Figure 5. Effect of fiiber addition on Young modulus of PP-coir composites.

Table 5. Effect of fiber addition on Young's modulus.

\begin{tabular}{lll}
\hline \% of fiber & $\begin{array}{l}\text { Young's Modulus for } \\
\text { treated fiber }\end{array}$ & $\begin{array}{l}\text { Young's Modulus for } \\
\text { untreated fiber }\end{array}$ \\
\hline 5 & 416.272 & 630.6 \\
10 & 426.6785 & 440.18 \\
20 & 476.2659 & 684.02 \\
25 & 411.653 & 798.6 \\
\hline
\end{tabular}

Young's Modulus is a measure of stiffness of a material. Thus, stiffness of the PP-Coir (treated) composite increases with the increase of fiber addition continuously. Young's modulus increase continuously for both treated and untreated fiber.

\subsection{Flex. Fracture Energy}

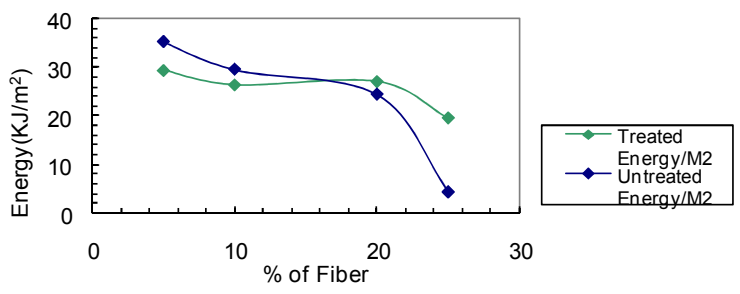

Figure 6. Effect of fiber addition on flexural energy fracture of $P P-C$ composite.

Figure 6 shows the effect of fracture energy of PP-Coir composites for treated and untreated fiber. The fracture energy of a material is a quantitative measure of the fracture toughness of it. The figure reveals that with the increase of fiber addition, fracture toughness in gradually decreases. This happens due to the fact that, with fiber addition composites specimen shows more brittle behavior and thus come to the peak load so quickly, which ultimately causes less area under the load-displacement curve. Similar effect was found by Md. Mydul Alam [8] and William D. Callister [9].

Table 6. Effect of fiber addition on fracture energy.

\begin{tabular}{lll}
\hline$\%$ of fiber & $\begin{array}{l}\text { Fracture Energy }(\mathrm{KJ} / \mathbf{m} 2) \\
\text { for treated fiber composites }\end{array}$ & $\begin{array}{l}\text { Fracture Energy }(\mathrm{KJ} / \mathbf{m} 2) \text { for } \\
\text { untreated fiber composites }\end{array}$ \\
\hline 5 & 29.4386 & 35.258 \\
10 & 26.437 & 29.588 \\
20 & 27.119 & 24.4588 \\
25 & 19.5174 & 4.4275 \\
\hline
\end{tabular}




\subsection{Elongation}

Figure 7 shows the effect of coir addition elongation of PP-coir composites. It reveals that the elongation of fabricated product decreases continuously with the increase of fiber addition. The presence of fiber restricts the slip resulting in lesser ductility and consequently the $\%$ of elongation decreases continuously with the increase of fiber addition. The figure shows that the $\%$ of elongation of the fabricated product is lesser than that of literature value. It is also due to lower density.

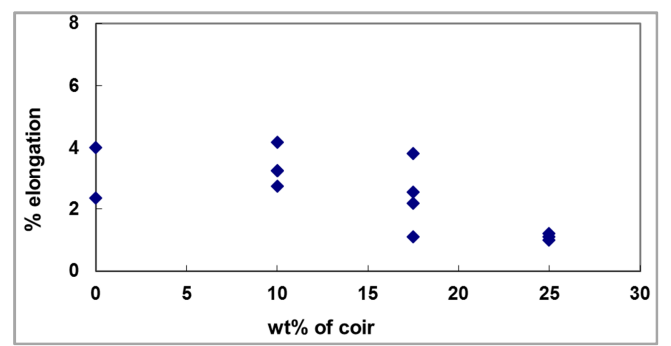

Figure 7. Effect of coir on elongation of PP-coir composites.

\section{Conclusion}

Based on the thesis work, following conclusion may be drawn.

Both for treated and untreated fiber, the flexural strength increases with the increase of fiber addition up to certain percentage. This limit indicates the best fraction of fiber in composites needed for reinforcement. Afterwards, the variation of flexural strength with composition is insignificant up to about $20 \%$ for fiber; the flexural strength is always higher than that for untreated fiber [10].

The flexural strength is always higher than that for untreated fiber composites. The tangent modulus increases with the increase of fiber addition up to certain percentage of addition treated and untreated fiber and after it decreases. Up to this composition (increasing region) the fiber and the polymer are well distributed.

The flexural strain of fabricated product decreases continuously with the increase of fiber addition. But here untreated fiber reinforced composites show higher strain than that of treated fiber reinforced composites.

\section{Nomenclature}

$\begin{array}{ll}\text { BD } & \text { Bulk Density } \\ \mathrm{Wt} & \text { Weight of the sample } \\ \mathrm{L} & \text { Length of the sample } \\ \mathrm{W} & \text { Width of the sample } \\ \mathrm{H} & \text { Height of the sample } \\ \mathrm{HDPE} & \text { High Density Polyethylene }\end{array}$

\section{References}

[1] Sahadat Hossain M, Uddin MB, Razzak M, Sarwaruddin Chowdhury AM, Khan RA. Fabrication and characterization of jute fabrics reinforced polypropylene-based composites: effects of ionizing radiation and disaccharide (sucrose). Radiation Effects and Defects in Solids. 2017 Dec 2; 172 (11-12): 904-14.

[2] Sahadat Hossain, Md, AM Sarwaruddin Chowdhury, and Ruhul A. Khan. "Effect of disaccharide, gamma radiation and temperature on the physico-mechanical properties of jute fabrics reinforced unsaturated polyester resin-based composite." Radiation Effects and Defects in Solids 172, no. 5-6 (2017): 517-530.

[3] Shahriar Kabir M, Hossain MS, Mia M, Islam M, Rahman M, Hoque MB, Chowdhury AM. Mechanical Properties of Gamma-Irradiated Natural Fiber Reinforced Composites. InNano Hybrids and Composites 2018 (Vol. 23, pp. 24-38). Trans Tech Publications.

[4] Hoque MB, Hossain MS, Nahid AM, Bari S, Khan RA. Fabrication and Characterization of Pineapple Fiber-Reinforced Polypropylene Based Composites. InNano Hybrids and Composites 2018 (Vol. 21, pp. 31-42). Trans Tech Publications.

[5] Rahaman MN, Hossain MS, Razzak M, Uddin MB, Chowdhury AS, Khan RA. Effect of dye and temperature on the physico-mechanical properties of jute/PP and jute/LLDPE based composites. Heliyon. 2019 Jun 1; 5 (6): e01753.

[6] A. Gafur And M. A. Rashid, Natural Fiber Reinforced Polymer (Coir-Hdpe) Matrix Composites- Fabrication, Process Parameters And Properties, $2^{\text {nd }}$ Bsme-Asme International Conference On Thermal Engineering, 2-4 Januray, 2004, Dhaka, Bangladesh, Voll-Ii, P. 1078-1082.

[7] M. A. Gafur, M N Hassan And Akram Hossain, Natural Fiber-Polymer (Jute-Ldpe) Matrix Composites - Its Fabrication, Process Parameter, And Properties, $3^{\text {rd }}$ International Conference On Mechanical Engineering And $8^{\text {th }}$ Apm On E-Manufacturing, Ieb Bangladesh, Me Div, 20-22 March, 2003, Paper No. 22, Dhaka, Bangladesh, P. 163-167.

[8] Bipasha Bose, Effect Of Water Absorption On The Mechanical Properties Of Jute Fiber Reinforced Polymer Composites, June, 2005.

[9] Herzog, R. O. And Jancke, W., Physik, Z., 1920, 3, 106.

[10] Shabname Ele, Development And Characterization Of Pp-Bagass Composites, December, 2003.

[11] Md. Akbar Hossain Miah, Reyad Mehfuz, Syed Misbah Uddin, Mechanical Properties Of Short Jute Fiber Reinforced Hdpe Composite.

[12] Sarce Report; Natural Fiber Conceret-Report From A Sarec Financed Research And Development Project Hans - Enik Gram $\mathrm{Ha}^{\circ}$ kan Persson $\mathrm{A}^{\circ}$ ke Sharendahl, P17.

[13] Md. Mydul Alam, Development Of A New Composite With Natural Fiber (Udal) And Synthetic Polymer (Ethylene Vinyl Acetate) And The Studies of Its Mechanical Properties, July, 2005.

[14] William D. Callister, Jr., Material Science and Engineering And Introduction. P130-131.

[15] Hull D An Introduction To Composite Materials, Cambridge University Press, 1981. 